\title{
Antenna Reconfiguration Techniques for Cognitive Radio: A Review
}

\author{
Ros Marie C CLEETUS* and Gnanadhas Josemin BALA \\ Department of Electronics and Communication Engineering, Karunya Institute of Technology and \\ Sciences, Coimbatore, Tamilnadu, India
}

('Corresponding author's e-mail: ros_bina@yahoo.in)

Received: 25 September 2019, Revised: 4 July 2020, Accepted: 2 August 2020

\begin{abstract}
As the usage of wireless communicative devices is multiplying day by day, the need for the occupiable radio spectrum is also increasing. The inefficiency in the exploration of available licensed radio spectrum has rerouted the focus to effectively use it against the increasing demand. One of the available methods is to implement Cognitive Radio (CR) technology. The Cognitive Radio uses 2 antennas at a time in order to scan and to communicate with the available spectrum. While an Ultrawideband (UWB) antenna scans the spectrum for unused bands of frequencies, Narrowband (NB) antennas communicate with these sensed unused bands. The technique of Reconfiguration in antennas is found to have a major role in implementing these UWB/NB antennas for CRs. Here in this paper, a survey is conducted on various reconfiguration techniques in antennas to build up a CR system. Each technique is studied in terms of the compactness, novelty, coverage of frequencies, and losses associated with the antenna. Finally, all the techniques are compared on the basis of their merits and demerits in this work.
\end{abstract}

Keywords: Cognitive radio, Frequency reconfigurability, Narrowband antenna, Sensing antenna, Ultrawideband antenna

\section{Introduction}

The wireless communication systems rely on the radio spectrum, which is found to have a limited resource. In this area, the policy that has been followed traditionally by the regulators is the Fixed Spectrum Access policy. A number of users are allowed a part of the spectrum with a specific bandwidth, in this policy. The major demerit that is found in this case is that only the licensed users are allowed to access the spectrum. Other unassigned users do not have access to it, even if the licensed users are not using it and or the spectrum remains unused. As the usage of wireless systems increased tremendously in this era, the scarcity of the spectrum is found to be affected. At the same time, the experiments on the available spectrum utilization came out with the conclusion that most of the licensed spectrum remain unused $[1,2]$. These situations triggered an efficient and flexible policy for the radio spectrum to be effectively used, Dynamic Spectrum Access policy [3]. In this policy, a number of users, called Primary Users are allotted with a part of the spectrum with high priority. If the spectrum is not being used by the Primary Users, some other users with least priority are able to access it, called Secondary Users. It is also possible for the Primary and Secondary Users to share the spectrum at a time. This is found to enhance spectrum utilization efficiency. In Dynamic Spectrum Access Policy, the secondary users have to sense, learn, and cooperate with the radio environment. Such Secondary Users are termed as Cognitive Radio or a Cognitive Radio user.

The cognitive radio varies its parameters according to the environment it is exposed to. It is dynamic and it is designed to sense the spectrum to find the vacant spectrum holes which are also known as white space. The spectral hole concept is illustrated in Figure 1 [4]. The 2 cognitive spectrum access 
http://wjst.wu.ac.th

models used extensively are, the opportunistic Spectrum Access Model (OSA) and the Concurrent Spectrum Access Model (CSA) [2].

The OSA model where the CR uses senses the spectrum to find the holes that remain vacant is shown in Figure 2. The RF architecture of an OSA model comprises a sensing antenna and a reconfigurable transmitter or receiver antenna. The sensing antenna is meant to sense the channel for unused bands of frequencies or spectrum holes and the reconfigurable antenna is used for communication with these spectrum holes [5]. The sensing antenna will normally be an Ultrawideband antenna (UWB antenna) and for CRs, the UWB frequency ranges from 3.1 to $10.6 \mathrm{GHz}$ [6]. Four bow-tie microstrip antennas were experimented with different materials and thicknesses to investigate the effect of material permittivity and dimensions on antenna performance, wherein the slot bow-tie is found to be 1 candidate for UWB applications [7]. In a Cognitive radio, the UWB antenna will communicate with the Spectrum Sensing module of the CR system. This module is continuously monitored for the vacant frequency channels within the coverage of the UWB antenna. The Spectrum Sensing module is connected to the Spectrum Decision module, which in turn decides the bands to be communicated with. The next module is the Switch Controller that is tuning the operating frequency of the connected Reconfigurable Antenna [8]. The antennas that are capable of reconfiguring themselves with respect to certain characteristics of the antenna, such as resonant frequency, radiation pattern, polarization, or any combinations of the above characteristics are considered as Reconfigurable Antennas [9]. In CRs, while the sensed spectrum hole is being utilized, there are possibilities that the Primary User may need the same channel. As the Primary User has the most priority, the Secondary User then will have to move to another spectrum hole to maintain the communication. For this, the antenna has to change its operating frequency to another band in the sensed spectrum. This requirement of antennas leads to the usage of Frequency Reconfigurable Antennas in Cognitive Radios.

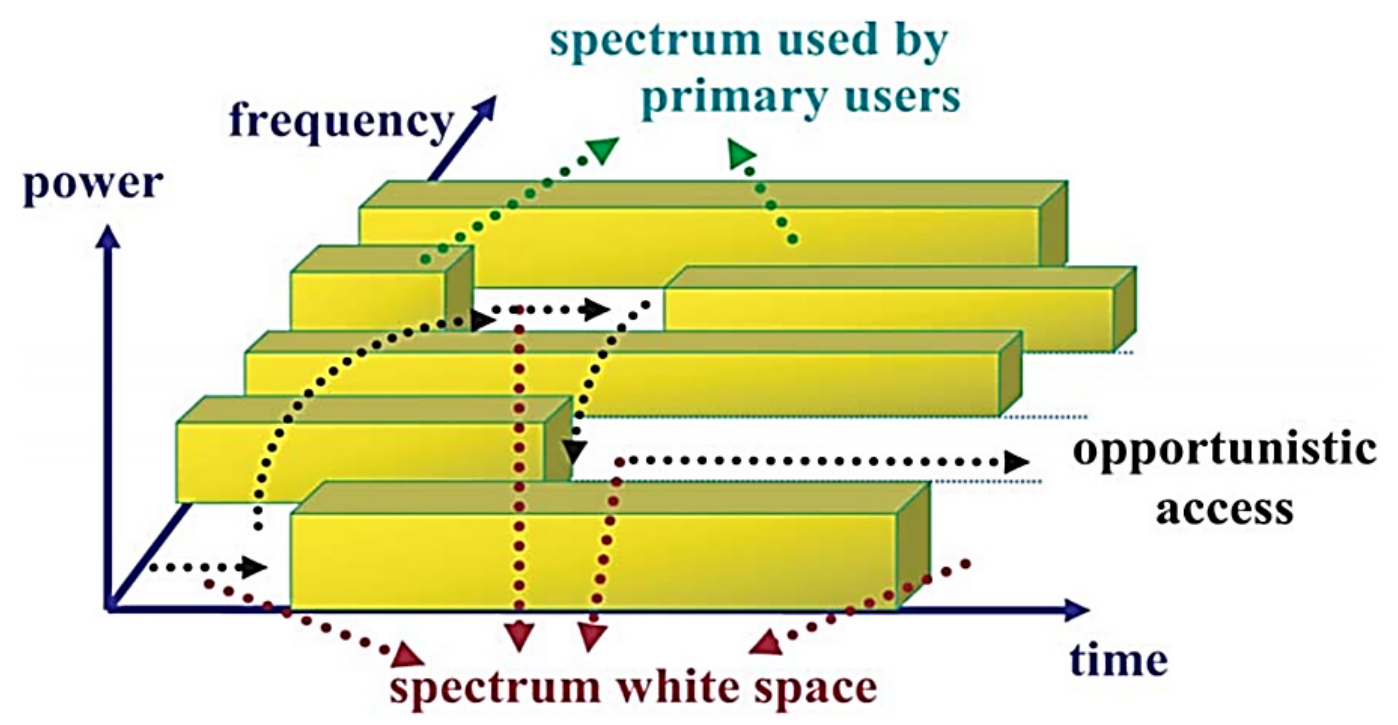

Figure 1 The spectral hole concept [4].

The reconfiguration techniques can be enlisted as Electrical, Optical, Physical, and Material change [10]. The electrical reconfiguration is based upon a few electronic switching components, such as PIN diodes, MEMS switches, varactor, FET switches, etc. The different switching status of these components results in the reconfiguration of antenna characteristics. The optical reconfiguration makes use of photoconductive switches controlled by a laser. In the Physical reconfiguration, structural alteration of the radiating structures is done to ensure reconfigurability. In the material change technique, the relative 
http://wjst.wu.ac.th

permittivity, permeability, etc. of the materials such as liquid crystals or ferrites provide reconfigurability. In addition to these, another reconfiguration technique for CR applications is presented recently in [11], called excitation switching reconfiguration with multiple numbers of Narrow Band antennas (NB antennas) and a reconfigurable switching method. Depending on the sensed spectral hole, the corresponding NB antenna communicates with the sensing antenna while all other NB antennas remain idle.

The literature in the field of antennas used for Cognitive radio applications introduced different systems according to the nature of the proposed designs. The spectrum sensing and communicating sections in a CR may or may not be supported by a single antenna. There are works that happened in this field which dealt with only the communicating section of a CR by properly implementing a frequency reconfigurable system to perform the band rejection $[13,14,50]$. The spectrum sensing for such antennas must be done by an external UWB covering design. The $2^{\text {nd }}$ category of designs are reported which consists of both the RF sensing and communicating parts incorporated in the same substrate, but as separate antennas $[11,15,31,32,37,41,42,45,49,53,54]$. The $3^{\text {rd }}$ category is found to be single structures that carry out both the RF sensing and RF transmission/reception by their own $[12,16,30,33,36,40,43,44,51]$.

Various Reconfiguration techniques used in CRs are listed in the following sections. In Section 2, various Electrical Reconfigurable antennas and in Section 3, different Optical Reconfigurable antennas are reported. Section 4 details a number of Physical Reconfigurable antennas and in Section 5 Material Change Reconfiguration are elaborated. Section 6 presents the newest technique, Excitation Switching Reconfiguration that will be followed by a comparison of the mentioned techniques and Conclusion.

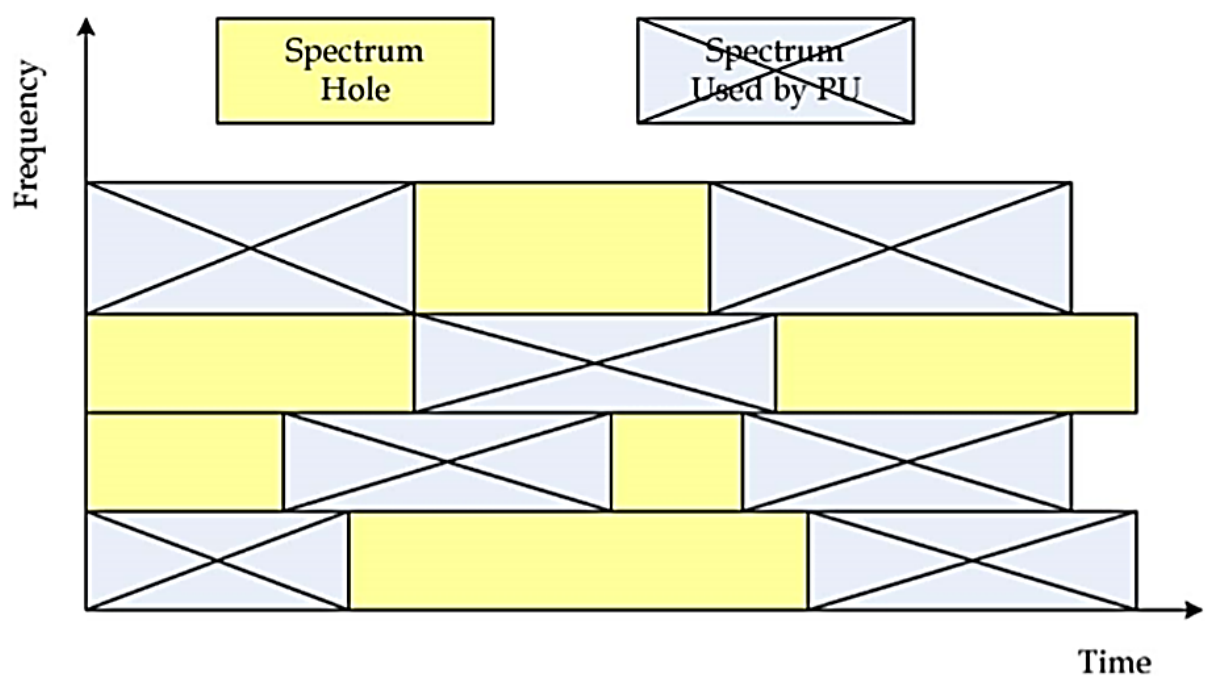

Figure 2 The opportunistic Access of spectrum by CR user [2]

\section{Electrical reconfiguration}

In Electrical reconfiguration, the electronic components such as MEMS, PIN diodes, varactors, FET switches, etc. are acting as switches and direct the surface current according to the switching status of the antenna. Switches are integrated into the antenna aiming for better isolation and fewer losses.

\section{Electrical reconfiguration based on MEMS switches}

A reconfigurable UWB antenna with a single notched band of frequency is presented in [12]. The wider bandwidth and better radiation are ensured by the octagonal shape of the radiating patch in this 
http://wjst.wu.ac.th

design. So as to ensure the UWB operation in the band 3.2 to $12 \mathrm{GHz}$, a partial ground plane is implied. Along with, by means of a MEMS switch inserted into the meandered slot on the octagonal patch, reconfigurability in the band $3.3-4.1 \mathrm{GHz}$ is accomplished. The MEMS switch is decreasing the probability of interference in the WiMAX band of 3.3 - 3.9 GHz. The ON state of the switch is ensuring the UWB operation whereas, the OFF state decides the band notch characteristics. The design layout, as well as the return loss plots of this design, are shown in Figure 3 and Figure 4, respectively.

A frequency reconfigurable pixel patch antenna designed for 3 narrow bands is presented [13] in which a single patch designed for operation at $10 \mathrm{GHz}$, is being connected both widthwise and lengthwise by identical patches called pixels. Altogether the pixels constitute a $3 \times 3$ pixel patch design. The connections among the patches are done with optimized MEMS switches, which alter the current distributions and hence provide reconfigurability. Another E-shaped patch antenna reconfigured with MEMS switches is presented in [14]. The designing of the antenna followed a nature-inspired optimization technique, called particle swarm optimization. The switching status of MEMS switches cause the slot in the design to change its dimension and almost twice the bandwidth is found to be obtained by the optimized E- shaped patch than the original one. Optimization is done with the MEMS switch circuit models as they provide the effects of the actual switch. Another combination of a UWB and an NB antenna with MEMS switches is reported in [15]. Two coplanar waveguides fed elliptical monopoles, one, with a U-shaped long slot and the other with 2 symmetrical inverted long L-shaped stubs as resonators. The activation or deactivation of the resonators is done with the MEMS switches. This work uses a new design approach for the switches so that no biasing lines are involved in it. The NB antenna covers 5.15 to $5.825 \mathrm{GHz}$ whereas the UWB antenna covers the entire UWB spectrum, from 3.1 to $10.6 \mathrm{GHz}$.

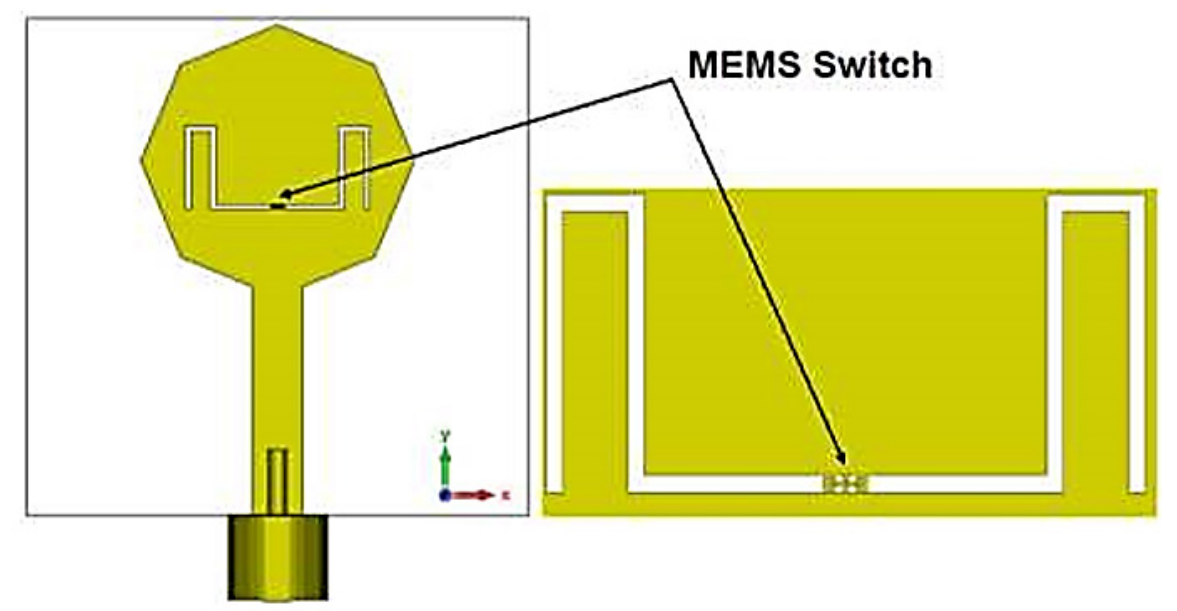

Figure 3 The Antenna Layout [12]. 
http://wjst.wu.ac.th

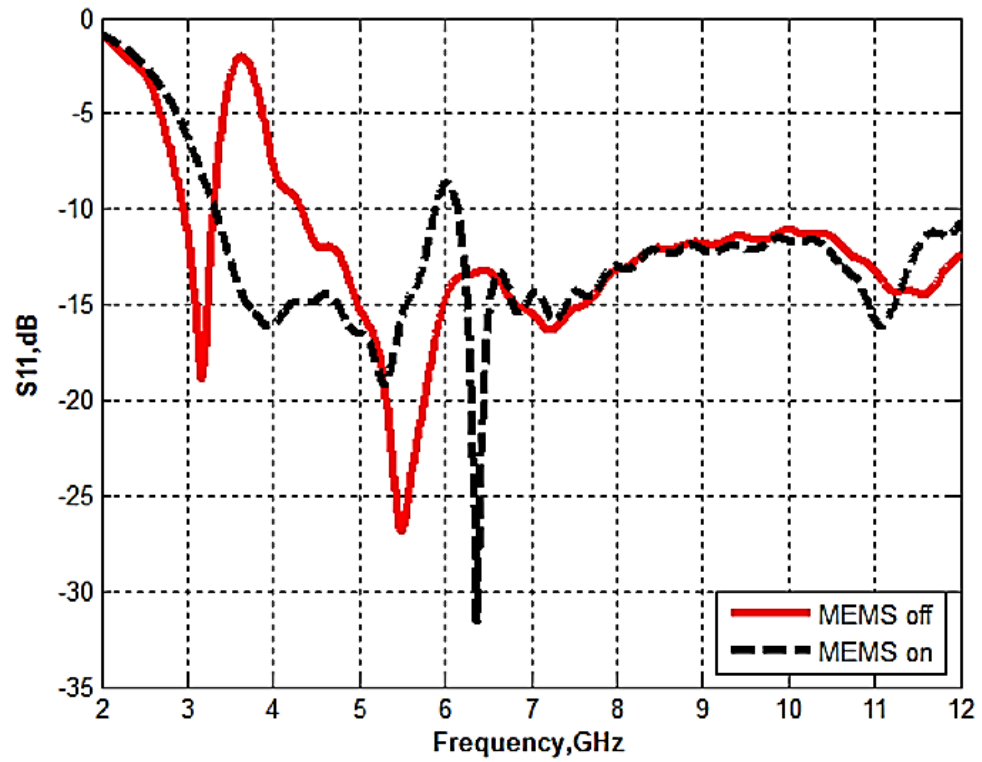

Figure 4 The return loss plots of the antenna at different switching instances [12].

\section{Electrical reconfiguration based on PIN diodes}

A stepped slot antenna with frequency reconfigurability and UWB characteristic is reported in [16]. The sensing section of the antenna that covers the entire UWB, from 2.8 to $10.7 \mathrm{GHz}$ is designed with stepped slots that are resonating in 3 bands within the UWB spectrum. The communicating section of the antenna is realized by different switching configurations of 5 PIN diodes, by covering 3 bands $3.2-4.5$, $4.3-7.8$ and $7.9-11.2 \mathrm{GHz}$ that cover the entire UWB spectrum. While most of the UWB/NB integrated antennas are not able to provide reconfigurability throughout the entire UWB, this antenna gives tunability over the entire spectrum by maintaining compact nature. The UWB slot antenna and Reconfigurable slot antenna with the diode connections are shown in Figure 5 and Figure 6, respectively.

Another UWB frequency reconfigurable patch antenna with slots inserted in patch and ground for improving the bandwidth is presented in [17]. The antennas are having similar patch structures but different ground plane configurations. Both the structures are able to operate in UWB and corresponding sub-bands, with switching implemented by PIN diodes integrated in the horizontal slot in the ground. The antenna reported in [18] is also made reconfigurable with switchable slots on the ground plane that is finding its applications in wireless multi-band systems. Another UWB/NB antenna configuration that uses 2 PIN diodes for switching is reported in [19]. The UWB antenna consists of a hairpin resonator that acts like a bandpass filter that produces a shunt effect on the ground. The filter is reconfigurable even without any switches. Whereas frequency reconfiguration is obtained by the PIN which switches placed on the arms of the resonator. Similarly, an antenna with a bandpass filter that is controlled by PIN diode switches is presented and studied the time domain characteristics such as impulse response, group delay, and fidelity factor [20]. This antenna finds another application in microwave imaging devices. Likewise, the housing effect is tested and explained on the prototype for assisting industrial engineers. 

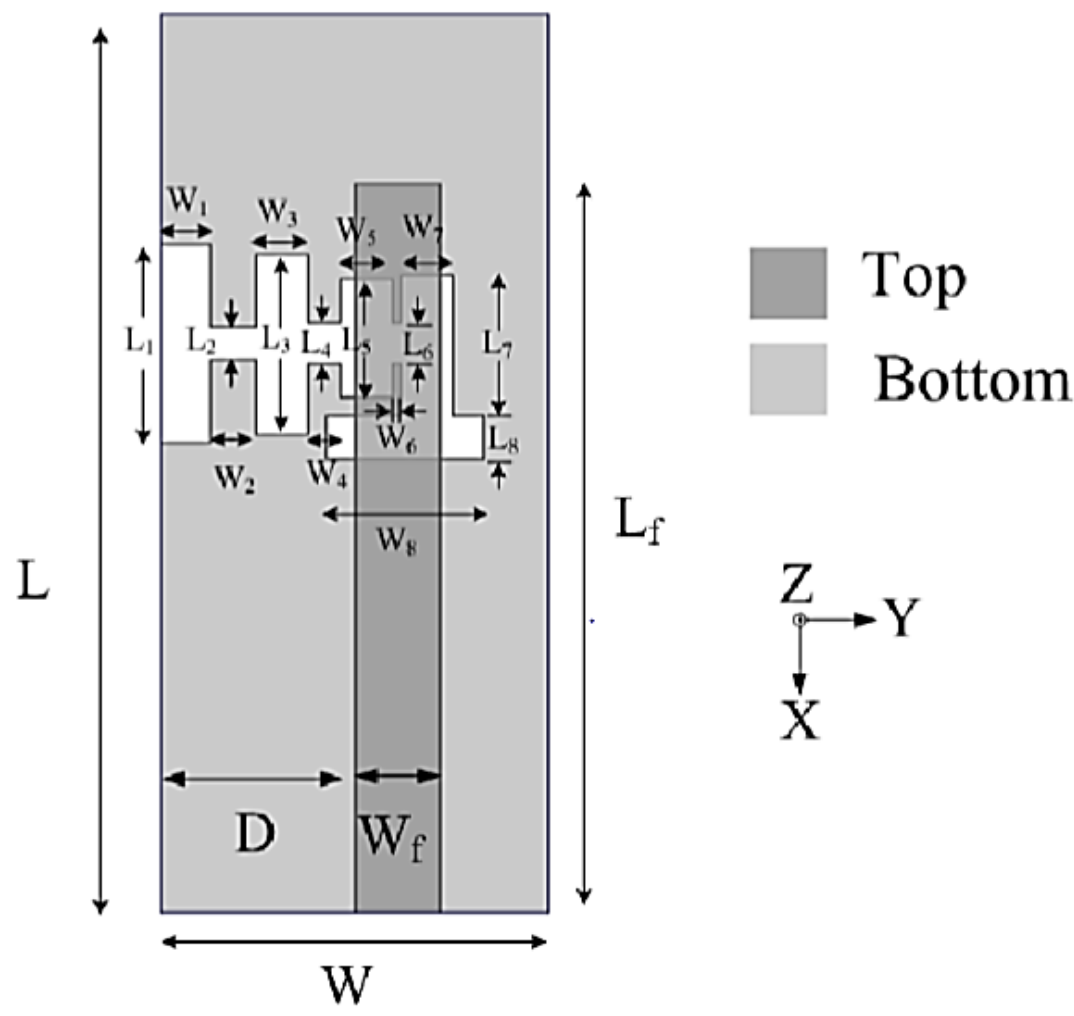

$\mathrm{L}_{f}$



Figure 5 The UWB slot antenna [16].

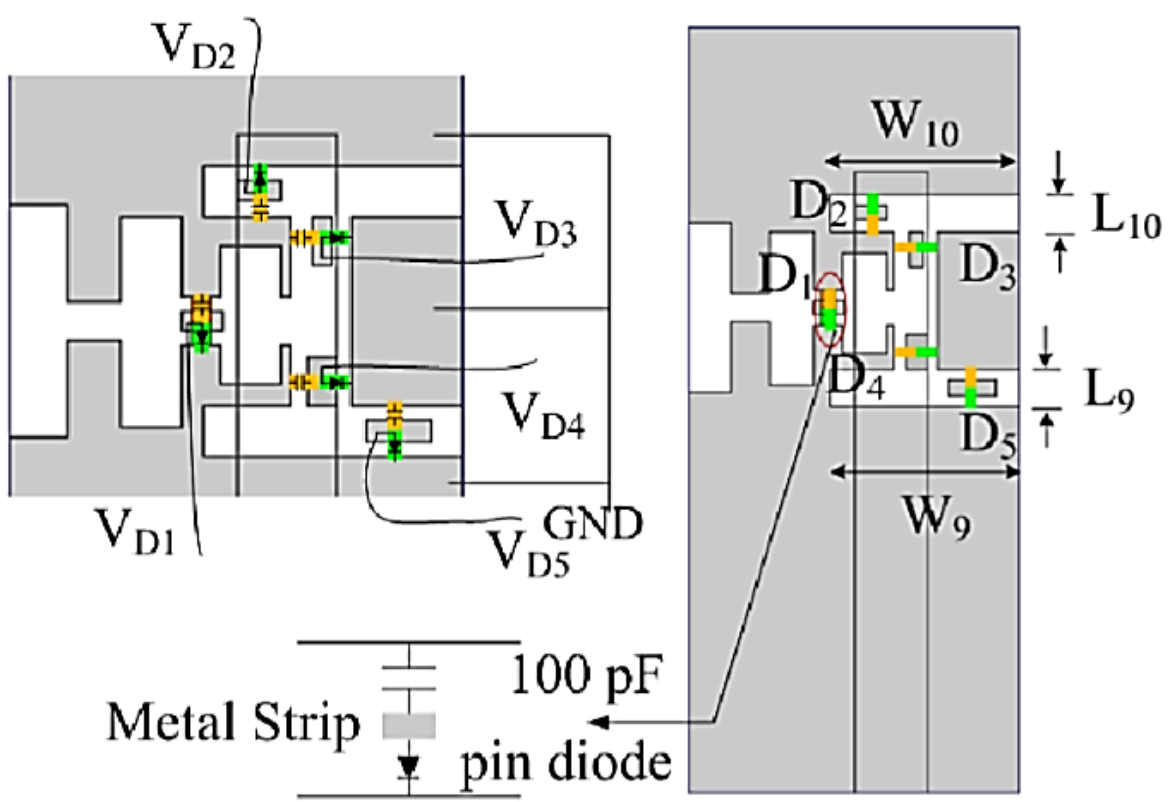

Figure 6 The Reconfigurable slot antenna with diode connections [16]. 
http://wjst.wu.ac.th

Another reconfigurable antenna that utilizes magneto-electric dipole technology is featured in [21]. Here the antenna structure is made with a wide band magneto-electric dipole that provides 1 wideband mode and a frequency reconfigurable narrowband dipole working in 4 narrowband modes. Switching between the narrow bands is accomplished by PIN diodes. The vertical dc lines are hidden from radiofrequency lines with the introduction of 4 metal posts with the magneto-electric dipole. This technique ensures more efficiency and less power losses. A frequency reconfigurable Vivaldi antenna that has a wideband operation from $2.5-12 \mathrm{GHz}$ made the frequency reconfigurable with a few hexagonal slots on the radiator in [22]. The PIN diode switches allow the antenna operation in 3 different narrow bands. It is reported that the insertion of additional PINs in between the slots causes the electrical length of the slot and hence the operating frequency to vary.

The antenna presented in [23] has filter structures in the feedline. The filters are reconfigured by means of PIN diode switches. The communicating section could be reconfigured in the band 5 - $10 \mathrm{GHz}$. The antenna structure is able to maintain an omnidirectional radiation pattern with above $70 \%$ efficiency in all cases. The antenna reported [24] is found to have the shape of conventional Inverted F Antenna, with the arm of monopole having a length of almost half wavelength. This causes the radiating structure to work as a slot. 5 PIN diode switches contribute to the switching where 4 of them are connected across the slot pairwise in a shunt configuration. The $5^{\text {th }}$ diode maintains a series connection across the gap in the monopole's long arm. Each of the sub-bands found to cover almost $10 \%$ bandwidth. The antenna provides an omnidirectional pattern as well as vertical polarization.

Another UWB/NB antenna combination is presented where the ultrawideband response is attained by a monopole antenna with a microstrip feeding mechanism. The reconfigurability is attained by cascaded split-ring resonators in the feedline using 7 PIN diode switches [25]. An Archimedean spiral antenna with a coplanar waveguide fed slot is reported in [26]. A pair of meandered slot lines with PIN diodes inserted is placed at both sides of the slot. These diodes provide reconfigurability in the $5.8 \mathrm{GHz}$ WLAN band as well as in a wide band ( 2 to $8 \mathrm{GHz}$ ). A UWB circular slot antenna that provides reconfigurability by means of PIN diodes in between the circular ring and a parasitic strip as well as a Tshaped stub is reported in [27].

A monopole antenna with switchable slots on the ground plane is explained in [28]. Reconfigurability is attained by 4 PIN diodes and it is reported that insertion of more diodes causes more narrow bands to be obtained. A reconfigurable double C-slot antenna is presented in [29], where frequency reconfigurability is attained by switching between 2 patches using 2 PIN diodes. The wideband mode of the antenna is attained by keeping both the switches ON. The radiation efficiency is found to be $80 \%$ and the gain ranges between $5-8 \mathrm{dBi}$.

\section{Electrical reconfiguration based on varactors}

A frequency reconfigurable filtenna with coverage of a sharp wideband and a few narrow bands is presented in [30]. The sensing section of the antenna covers 2.35 to $4.98 \mathrm{GHz}$. To switch the filtenna between the sensing and communicating parts, a PIN diode is used. The sensed band is free of notched dip by means of a square tapered line structure. The $\mathrm{C}$ shaped resonator is having 2 varactor diodes that allow shifting of operational frequencies from 3.05 to $4.39 \mathrm{GHz}$. The tunable bandwidth is observed as 36 $\%$. The sensing state has a unique out of band rejection characteristics. The fabricated prototype is shown in Figure 7.

Another antenna that is able to provide a wide range of operating frequencies using varactor diodes is presented in [31]. The antenna design is annular slot based which is planar and easy to get integrated with remaining circuit components. A comparison of annular or closed-loop slot-based antenna and open slot-based antenna is reported in this work. Open slot-based antennas depend mostly on the PIN diodes for reconfigurability and reactive loading for such antennas is difficult, hence wideband coverage is practically impossible to obtain. Whereas, the annular or closed-loop slot-based antennas are advantageous than the open slot-based designs due to mild variations in resonance frequencies of simulated and measured plots. A reconfigurable bandpass filter is implemented in [32] to obtain wideband as well as narrowband responses simultaneously. The switching of the filter in between wideband and narrowband responses is done by a PIN diode whereas 2 varactors are controlling the reconfigurable part 
http://wjst.wu.ac.th

of the antenna to switch between the resonant frequencies. The biasing network does not affect the radiations much and the antenna is providing better out of band rejection.
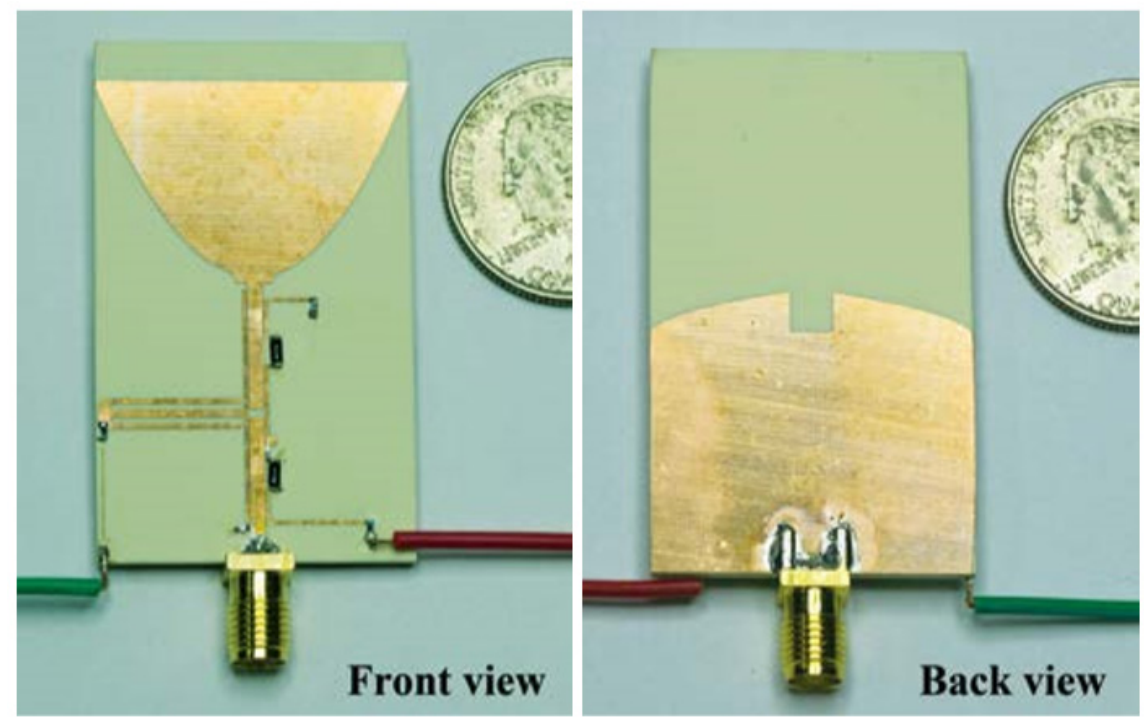

Figure 7 The fabricated prototype [30].

\section{Electrical reconfiguration based on FET switches}

An ultrawideband monopole antenna is reconfigured using Gallium Arsenide Field Effect Transistor switches (GaAs FET Switches) to obtain multiple narrow bands within the UWB spectrum is discussed in [33]. A number of stubs of varied lengths are connected to the main feedline using GaAs FET switches. The biasing method of the switches are reportedly simple that it will not affect the radiations adversely. Along with this, the switches are found to have low ON resistance and insertion loss. Hence the efficiency and gain of the antenna are not affected badly by the switching mechanism. Shifting from UWB to NB mode, the peak gain is found improved, the total efficiency does not go down considerably but filtering happens effectively. Power consumption is maintained at a low level. The antenna integration into portable devices and cognitive radios are relatively simple. The top and bottom views of the antenna are shown in Figure 8a and 8b, respectively. 


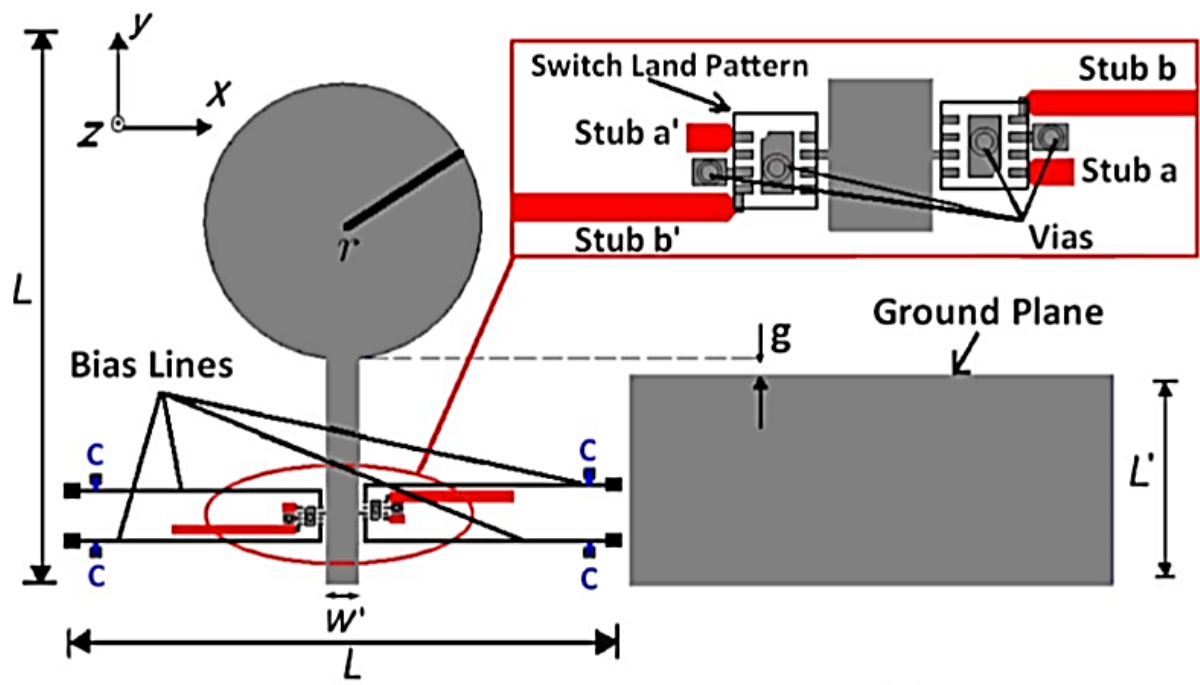

(a)

Figure 8 Antenna structure (a) Top View (b) Bottom View [33].

A number of antennas with reconfigurable section that can be realized by electronic switches, but not specified the type of switches are reported [34-37]. An antenna with a circular ring structure working in the fundamental mode, TM11 is detailed in [34]. Comparing to normal circular patch antennas or the antennas working in TM12 mode, circular ring antennas have a better bandwidth and quality factor. The fabricated antenna structure is shown in Figure 9. The substrate chosen is FR4 epoxy with relative permittivity 4.4. Six parasitic elements are attached to the main feedline using 6 switches. Six pieces of copper tape are inserted in the place of switches for the prototype validation. These copper tapes are inserted and removed in order to make the switches ON and OFF respectively. The authors suggest that the copper tape pieces can be replaced by active switches such as PIN diodes and MEMS. The reconfiguration in frequency is attained by varying the switching configurations of the antenna. Even with the parasitic elements, the antenna is found to exhibit UWB response, if all the switches are OFF. This configuration thus is used to sense the RF spectrum. The other switching configurations allow the antenna to work in NB modes so as to facilitate the communication with the unused bands. To improve the bandwidth and matching, a slit is introduced in the ground plane of the antenna system. The Vector Network Analyzer, Model N5230A of Agilent Technologies is used in the measurement of results.

Another combination of an integrated UWB/NB antenna that can be used by any of the electronic switches to achieve reconfiguration is explained in [35]. The rectangular patch is provided with 4 slots cut at the corner, which will lead to electrical length variation of the antenna that affects the resonant frequencies. A butterfly-shaped monopole antenna with UWB characteristics and reconfigurable notches is reported in [36]. The notches are obtained by introducing circular split ring pairs on the radiating patch. Two monopole antennas share a partial ground plane in [37], where the $1^{\text {st }}$ one senses the channel for unused frequencies in the entire UWB spectrum and the $2^{\text {nd }}$ one communicates using 8 bands from $3-10$ $\mathrm{GHz}$ by 4 switching cases. The comparison of the referred antennas such as, the antenna dimension, UWB coverage by the antenna in GHz, Different NBs the antenna covers by frequency reconfiguration are listed in Table 1. It can be observed that even though some antennas, [15-19,22,28,33,34,36,37] cover the entire UWB, those cannot fully cover the UWB as NBs, through reconfiguration. 
Table 1 The comparison of Electrically reconfigurable antennas.

\begin{tabular}{|c|c|c|c|}
\hline $\begin{array}{l}\text { Reference } \\
\text { No. }\end{array}$ & Antenna dimension & UWB coverage $(\mathrm{GHz})$ & NB coverage $(\mathrm{GHz})$ \\
\hline$[12]$ & $30 \times 30 \times 1.6 \times 10^{3}$ & 3.2 to 12 & 3.3 to 4.1 \\
\hline [13] & $60 \times 60 \times 1.6 \times 10^{3}$ & NA & $10.2,5$ and 3.8 \\
\hline [14] & $\begin{array}{l}120 \mathrm{~mm} \times 100 \mathrm{~mm} \times \mathrm{t} 1=10 \mathrm{~mm}, \mathrm{t} 2 \\
=1.574 \mathrm{~mm}\end{array}$ & NA & 2 to 3.2 \\
\hline [15] & $26.88 \times 20.7 \times 10^{3}$ & 3.1 to 10.6 & 5.150 to 5.825 \\
\hline [16] & $21 \times 9 \times 0.8 \times 10^{3}$ & 2.8 to 10.7 & $\begin{array}{l}3.2 \text { to } 4.5,4.3 \text { to } 7.8 \text {, and } 7.9 \\
\text { to } 11.2\end{array}$ \\
\hline [17] & $29 \times 28 \times 10^{3}$ & 3.1 to 10.6 & $\begin{array}{l}3.46 \text { to } 5.96,3.28 \text { to } 6.26 \text {, } \\
9.04 \text { to } 9.526\end{array}$ \\
\hline [18] & $40 \times 40 \times 1.33 \times 10^{3}$ & 2.54 to 11.71 & $\begin{array}{l}\text { Multi bands between } 2.34 \text { and } \\
7.42\end{array}$ \\
\hline [19] & $20 \times 25.32 \times 1.6 \times 10^{3}$ & 1.9 to 29.5 & 9.2 to 10.4 \\
\hline [20] & Not specified & 1.6 to 6 & 3.39 to 3.80 \\
\hline [21] & $240 \times 240 \times 48 \times 10^{3}$ & 0.83 to 2.16 & $\begin{array}{l}0.9 \text { to } 1,1.1 \text { to } 1.5,1.6 \text { to } 1.8 \text {, } \\
1.85 \text { to } 2.1\end{array}$ \\
\hline [22] & $82 \times 74 \times 1 \times 10^{3}$ & 2.5 to 12 & $\begin{array}{l}2.5 \text { to } 2.7,6.4 \text { to } 7,10.2 \text { to } \\
11.6\end{array}$ \\
\hline [23] & $38 \times 44 \times 1.6 \times 10^{3}$ & 3.1 to 10 & $\begin{array}{l}6.33 \text { to } 7.07,5 \text { to } 5.6,5.37 \text { to } \\
6.28,5.9 \text { to } 6.86,8.83 \text { to } \\
10.15\end{array}$ \\
\hline [24] & $25 \times 45 \times 0.8 \times 10^{3}$ & 6 to 10.6 & $6.7,7.3,8,8.7,9.6$ \\
\hline$[25]$ & $50 \times 70 \times 1.6 \times 10^{3}$ & 2 to 10 & $7.55,7.80$ and 8.90 \\
\hline [26] & $60 \times 69 \times 1.6 \times 10^{3}$ & 2 to 8 & 5.1 to 5.9 \\
\hline [27] & $45 \times 40 \times 1.6 \times 10^{3}$ & Not specified & 5.15 to 5.825 and 3.7 to 4.2 \\
\hline [28] & $40 \times 40 \times 1.6 \times 10^{3}$ & 2.95 to 10.92 & $\begin{array}{l}2.11 \text { to } 2.8,2.24 \text { to } 2.72,3.32 \\
\text { to } 3.79,5.15 \text { to } 5.9 \text { and } 5.14 \text { to } \\
5.9\end{array}$ \\
\hline [29] & $50 \times 50 \times 1.57 \times 10^{3}$ & 4.99 to 7 & 5,6 bands \\
\hline [30] & $50 \times 30 \times 1.524 \times 10^{3}$ & 2.35 to 4.98 & 3.05 to 4.39 \\
\hline [31] & $60 \times 120 \times 1.5 \times 10^{3}$ & 0.75 to 7.65 & 1.77 to 2.51 \\
\hline [32] & Not specified & 3.8 to More than 6 & 3.9 to 4.82 \\
\hline [33] & $50 \times 50 \times 1.52 \times 10^{3}$ & 2 to 11 & $\begin{array}{l}2.1 \text { to } 2.6,3.6 \text { to } 4.6,2.8 \text { to } \\
3.4,4.9 \text { to } 5.8\end{array}$ \\
\hline [34] & $40 \times 40 \times 1.6 \times 10^{3}$ & 3.1 to 10.6 & $\begin{array}{l}6.55 \text { to } 6.64,3.5 \text { to } 4.3,8.34 \\
\text { to } 8.87,5.44 \text { to } 6.18,7.43 \text { to } \\
7.63 .10 .15 \text { to } 10.65\end{array}$ \\
\hline [35] & $40 \times 40 \times 1.6 \times 10^{3}$ & 3.02 to 9 & $\begin{array}{l}3.45 \text { to } 6.45,5.04 \text { to } 7.65 \text { and } \\
7.04 \text { to } 8.58\end{array}$ \\
\hline [36] & $33 \times 24 \times 1.6 \times 10^{3}$ & 3.1 to 10.7 & 3.31 to $3.74,5.03$ to 5.94 \\
\hline [37] & $50 \times 50 \times 1.6 \times 10^{3}$ & 3 to 10.6 & $\begin{array}{l}8 \text { bands in } 4 \text { cases between } 3 \\
\text { and } 10\end{array}$ \\
\hline
\end{tabular}




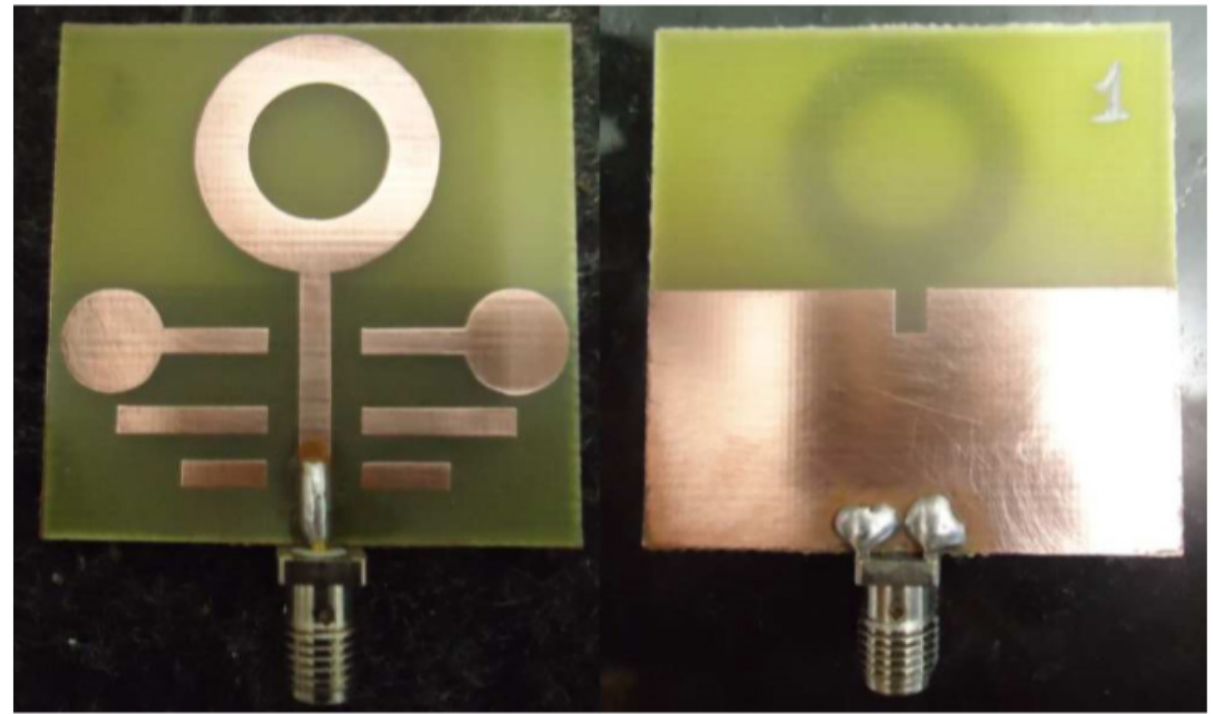

Figure 9 The fabricated antenna, front view (left side) and back view (right side) [34].

\section{Optical reconfiguration}

The reconfiguration technique that uses photoconductive switches to alter the direction, as well as the radiating properties of an antenna, is termed as Optical reconfiguration. An optically controlled reconfigurable antenna that performs both sensing and communication is presented in [40]. The reconfiguration is achieved by means of switching combinations of 4 photoconductive switches and 3 narrow bands have resulted within 2.65 to $10.3 \mathrm{GHz}$. The antenna structure is shown in Figure 10. No biasing lines are needed in this case as in electronic reconfiguration. The switches are electromagnetically transparent and no interferences are introduced with the radiations of the antenna. Both electrical and thermal isolations are provided between the control circuitry and the antenna.

Another antenna structure having both UWB and reconfigurable unit where the active and dark states of the Si switch are controlled by Infrared Emitting Diodes $(880 \mathrm{~nm})$ is discussed in [41]. The medium and high resistive $\mathrm{Si}$ is compared in terms of conductivity of both active and dark states and found that high resistive Si gives the best performance. An optically controlled reconfigurable antenna with a U-shaped monopole antenna for sensing the spectrum and an open annulus antenna for communicating with the spectrum using 4 photoconductive switches is presented in [42]. Another compact antenna structure is presented with a U-shaped resonator as a UWB antenna in [43]. A folded slot is inserted onto the patch with 5 photoconductive laser-controlled silicon chips and by the switching action of these, a number of notched bands resulted. Different switching configurations end up with varying effective lengths of the slot and hence the notched bands vary. The switches are found to have electromagnetic transparency and a reduced effect on antenna radiations.

An antenna structure that uses 2 Optically Controlled Microwave Switches (OCMS) for its reconfigurable part is detailed in [44]. The OCMS are found to be advantageous in terms of less power of almost $100 \mathrm{~mW}$ needed for operation, good isolation between controlled and controlling signals and faster switching action. The frequency reconfigurability of the cognitive antenna reported in [45] is achieved by photoconductive switches that are controlled by laser diodes integrated within the antenna itself. It makes the antenna to be easily integrated into commercial wireless systems. The comparison of the referred antennas such as the antenna dimension, UWB coverage by the antenna in GHz, Different NBs the antenna covers by frequency reconfiguration are listed in Table 2. It can be observed that the antennas 
reported in [42-45] cover the entire UWB. But none of these designs fully cover the UWB as NBs by the optical reconfiguration method.

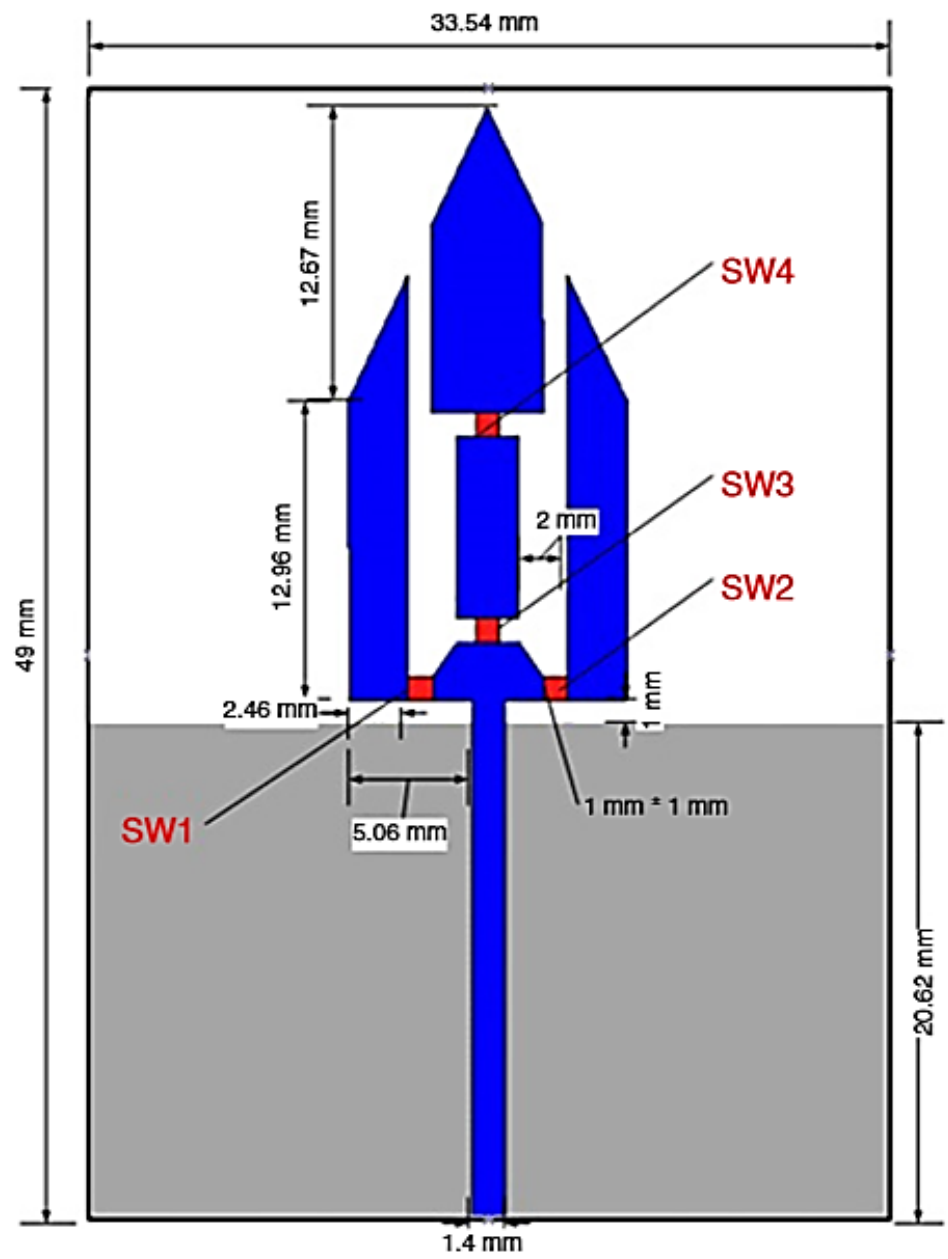

Figure 10 The antenna structure [40].

Table 2 The comparison of Optically reconfigurable antennas.

\begin{tabular}{|c|c|c|c|}
\hline Reference & Antenna dimension & $\begin{array}{c}\text { UWB coverage } \\
(\mathrm{GHz})\end{array}$ & $\begin{array}{l}\text { NB coverage } \\
(\mathrm{GHz})\end{array}$ \\
\hline$[40]$ & $49 \times 33.54 \times 0.8 \times 10^{3}$ & 2.65 to 10.3 & 3.55 to $5.18,5.12$ to $6.59,7.10$ to 8.01 \\
\hline [41] & $90 \times 60 \times 0.16 \times 10^{3}$ & 2.5 to 8 & Resonant frequencies at $3.9,6.2$ \\
\hline [42] & $40 \times 38.5 \times 0.5 \times 10^{3}$ & 3 to 11 & 5.8 to $6.8,6.7$ to $7.3,7.0$ to $8.4,7.9$ to 9.2 \\
\hline [43] & $25 \times 25 \times 0.8 \times 10^{3}$ & 2.1 to 11 & 2.2 to $2.9,3.2$ to $4.7,4.8$ to $6.6,7.5$ to 8.7 \\
\hline [44] & $40 \times 35 \times 1.5 \times 10^{3}$ & 2.62 to 11 & Dual notches centered at 3.56 and 5.1 \\
\hline$[45]$ & $50 \times 45.5 \times 1.6 \times 10^{3}$ & 3 to 11 & 3.2 to $4.3,4.15$ to $5.1,4.8$ to 5.7 \\
\hline
\end{tabular}




\section{Physical reconfiguration}

Physical reconfiguration in antennas is attained by means of structural alterations associated with the radiators. A 2-port antenna system with a UWB section and a reconfigurable section is presented in [46]. Five patches are used in the reconfigurable section where the rotational motion of the patch by a stepper motor allows the $2^{\text {nd }}$ port to be connected to any of the 5 patches at a time. A microcontroller is used to control the stepper motor by a MEMS switch. The reconfigurable section is advantageous in terms of easier fabrication and installation. The sensing and reconfigurable sections of the antenna are shown in Figure 11a and 11b, respectively. The sensing section covers a wide band from $2.1-10.6 \mathrm{GHz}$. The reconfigurable section is found to cover the entire UWB spectrum.

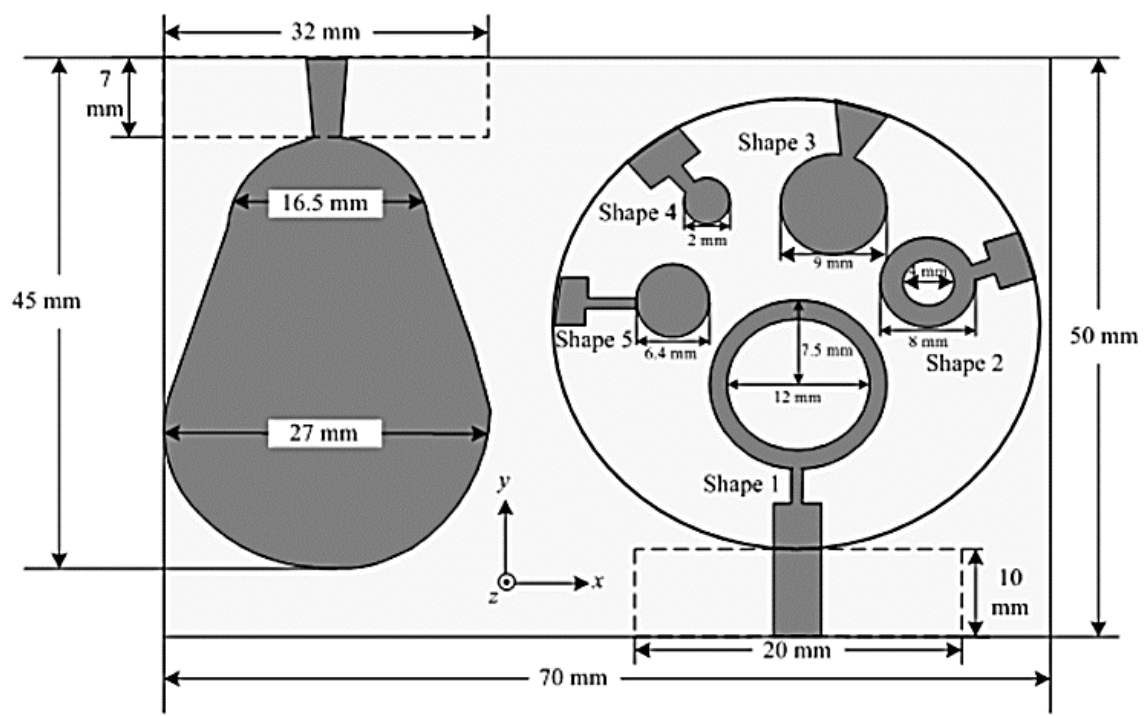

(a)

(b)

Figure 11 The antenna design (a) Sensing section (b) Reconfigurable section [46].

Similar to the previous work, antennas reported in [47] and [48] also depend upon the rotational motion of the patch. Whereas in [48], the rotational motion of the patch is controlled by a stepper motor that is connected to the parallel port of a computer through LABVIEW. An NPN Darlington array is employed as the intermediate between the stepper motor and the parallel port of the computer system. This antenna can also be tuned to the entire band sensed by the UWB section. In [47], it is noted that the coupling between the sensing and reconfigurable sections lies less than $-20 \mathrm{~dB}$ which is highly appreciable. It has become possible as the antennas are fed from opposite ends of the substrate. The reconfigurable section of the antenna presented in [49] has a triangular patch and for this also, reconfiguration becomes possible with the rotational motion of the patch. Even though the sensing antenna covers the whole UWB in this case, unlike the previous designs, the reconfigurable section only covers 2 bands, i.e., $3.4-4.85 \mathrm{GHz}$ and $5.3-9.15 \mathrm{GHz}$. The reconfigurable section is not able to tune the UWB fully in this design. The basic design of the previously mentioned works [47-49], is reported by the authors in [50]. This deals with only the reconfigurable section of the antenna, not the sensing section. Hence it is a uniport device. The rotating part is circular in shape and 4 patches are incorporated within it. In different instances, different patches are fed and different operating frequencies have emerged. The comparison of the referred antennas such as, the antenna dimension, UWB coverage by the antenna in GHz, Different NBs the antenna covers by frequency reconfiguration are listed in Table 3. It is reported 
http://wjst.wu.ac.th

that the antenna [46] covers the entire UWB from 3.1 to $10.6 \mathrm{GHz}$, and it is physically reconfigured to cover the entire UWB as NBs, even though the measured results are not included in the paper.

Table 3 The comparison of Physically reconfigurable antennas.

\begin{tabular}{|c|c|c|c|}
\hline Reference & Antenna dimension & $\begin{array}{l}\text { UWB coverage } \\
\text { (GHz) }\end{array}$ & NB coverage $(\mathrm{GHz})$ \\
\hline [46] & $70 \times 50 \times 1.6 \times 10^{3}$ & 2.1 to 10.6 & $\begin{array}{l}2.3 \text { to } 4.5,3.8 \text { to } 5,4.8 \text { to } 7.4,6.3 \text { to } 8.2 \text {, } \\
8 \text { to } 10.6\end{array}$ \\
\hline [47] & $70 \times 50 \times 1.6 \times 10^{3}$ & 2 to 10 & 5 bands within 2 to 10 spectra \\
\hline [48] & $70 \times 50 \times 1.6 \times 10^{3}$ & 2 to 10 & $\begin{array}{l}2.1 \text { to } 3,3 \text { to } 3.4,3.4 \text { to } 5.56,5.4 \text { to } 6.2 \text {, } \\
6.3 \text { to } 10\end{array}$ \\
\hline [49] & $58 \times 65.5 \times 1.6 \times 10^{3}$ & 3.3 to 11 & 3.4 to $4.85,5.3$ to 9.15 \\
\hline [50] & $50 \times 50 \times 1.6 \times 10^{3}$ & NA & $\begin{array}{l}2.3 \text { to } 2.6,2.6 \text { to } 3.4,4 \text { to } 5,3 \text { to } 4 \text {, } \\
5.26 \text { to } 7\end{array}$ \\
\hline
\end{tabular}

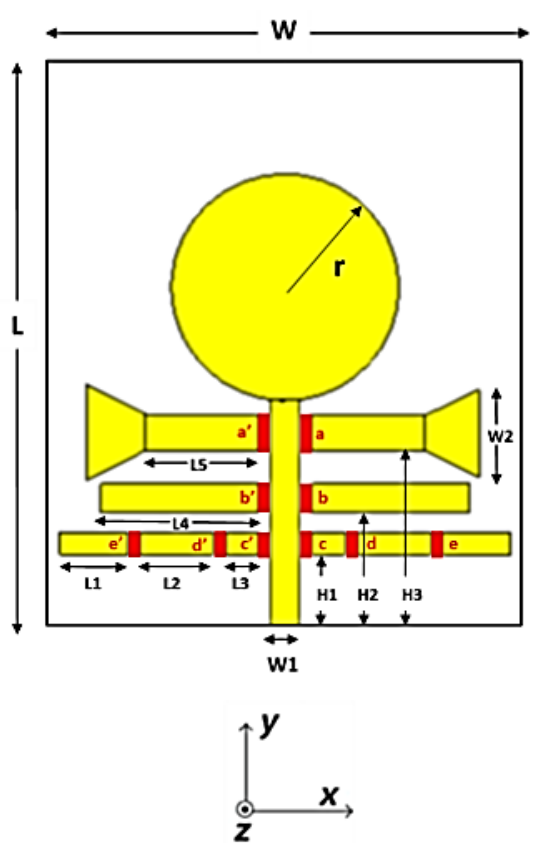

a) Front

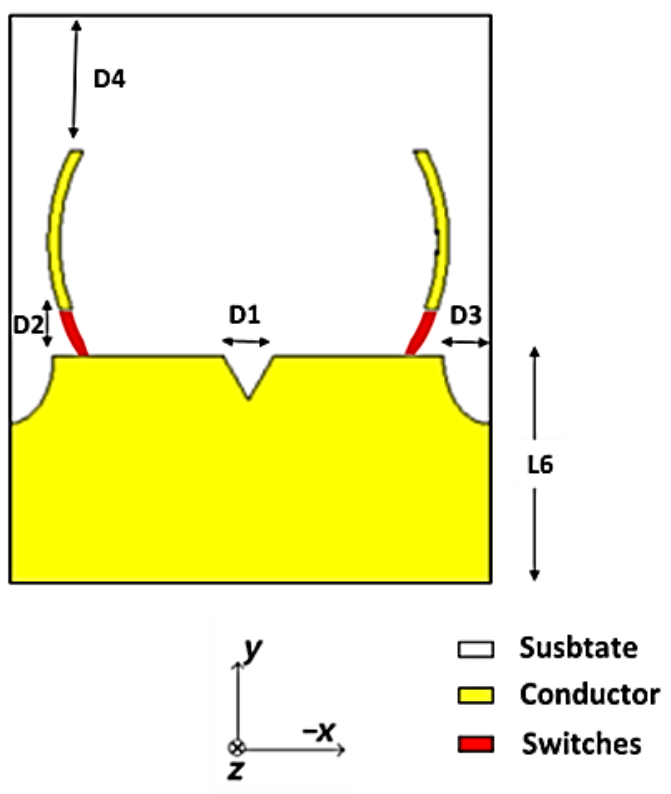

b) Back

Figure 12 The antenna design (a) Front view (b) Back view [51].

\section{Smart materials based reconfiguration}

A UWB wearable reconfigurable antenna is presented in [51]. Reconfiguration in frequency and pattern is attained using conductive thread embroidery on a textile-based antenna. The antenna is designed so as to use it in military uniforms or ordinary garments. A parametric analysis is conducted on the fabric substrate, such as cotton and leather. For the fabrication of the patch and ground on the substrate, 2 methods have been chosen, either by the usage of conductive thread embroidery on the textile 
http://wjst.wu.ac.th

substrate or by cutting copper textile sheets with a laser cutter and pasting it on the substrate. In the antenna design, stubs of different lengths are connected to the main feedline using switches and different switching combinations which lead to different radiation lengths and current densities resulted in different resonant frequencies. Any of the 2 semi-elliptical stubs connected on the back, when connected to the ground plane provides different radiation patterns. The UWB antenna scans from 3 to $8 \mathrm{GHz}$. And the NBs the antenna is found to cover are $2.4,3.2$ to $4.2 \mathrm{GHz}, 4.1$ to $5.4,5$, and 6.5 to $7.5 \mathrm{GHz}$. The front and back views of the antenna are shown in Figure 12a and 12b, respectively.

\section{Excitation switching reconfiguration}

The excitation switching reconfiguration technique ensures efficient utilization of spectrum by means of multiport UWB and NB systems. One UWB antenna and more than 1 NB antennas are placed on the same substrate for spectrum sensing and communicating with it respectively. Not as in other techniques, here the radiating parts of a single antenna are not undergoing any switching but the NB antennas as a whole getting switched as per the excitation from a source signal. The NB antennas are selected in such a way that proper matching is employed with the sensed holes or unused bands in the frequency spectrum, by the UWB antenna. The rest of the NB antennas are remaining idle at that time. The number of NB antennas is decided by factors like space, isolation, cost, number of parallel communication links and, bandwidth [52].

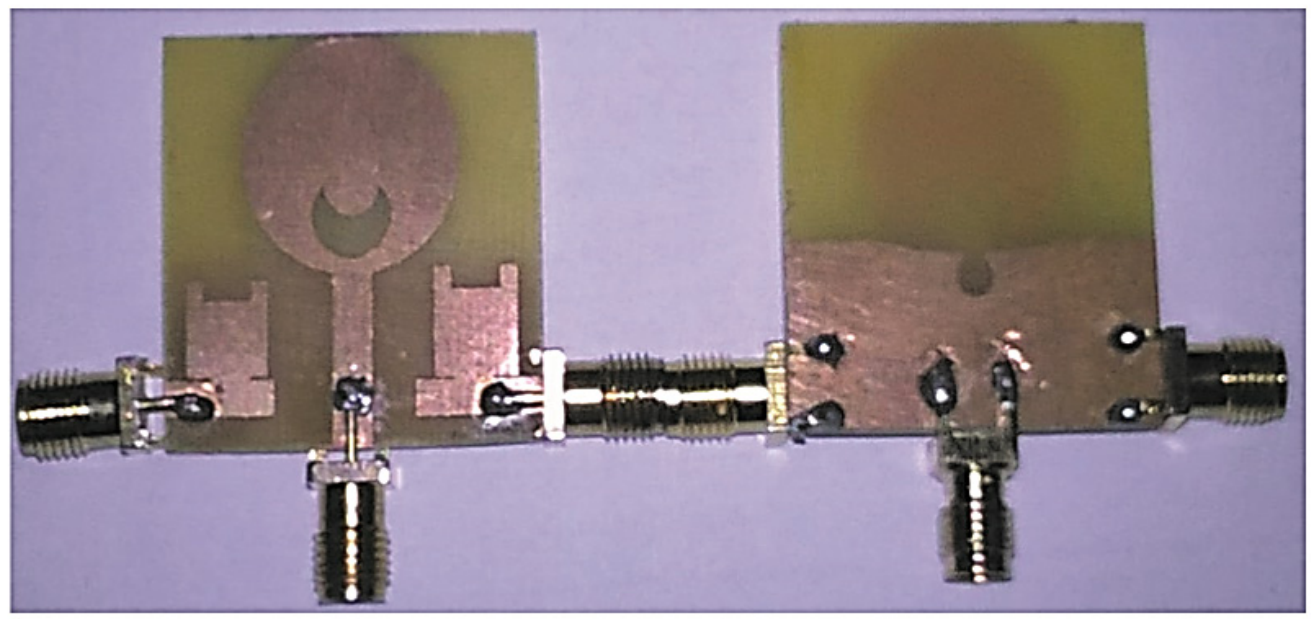

Figure 13 The front and back views of the Fabricated antenna [53].

A 3-port integrated antenna design is presented in [53]. The UWB antenna associated with the $1^{\text {st }}$ port senses the spectrum for unused frequency bands. Two NB antennas from the other 2 ports are meant for communication. To achieve better isolations, the patch, substrate, and ground of the antenna are carefully considered. There are possibilities that the NB antennas can be reconfigured by other reconfiguration techniques such that only 1 of those operates at a time. A number of slots are added at the top and bottom layers to improve the reflection characteristics. Both the narrowband antennas are found to cover dual bands. The slot on the patch found to vary the electrical length and hence the upper band of resonance whereas the stub inserted on the line controls the lower band. The design equations for length and width of the rectangular patch antenna will not be followed here because of the reduced size, coupling effects, and shape irregularities of the design. And the NB antennas are found to result in improved isolations. The front and back views of the fabricated antenna is shown in Figure 13. 
http://wjst.wu.ac.th

A 5-port integrated antenna system is presented in [11] where the 4 NB antennas altogether cover the entire UWB spectrum with less than $16 \mathrm{~dB}$ isolation, and better reflection characteristics. The compactness of the system, improved performance, simplicity, and cost-effectiveness are counted as the advantages of the system which make this antenna suitable for the CR environment.

The antenna reported in [54] is a compact 4-port design that consists of a UWB antenna which is fed by the coplanar waveguide and 3 rectangular loop antennas. The loop antennas are found to cover the entire UWB band. Even without any decoupling structures, this design exhibits isolation of greater than $17.3 \mathrm{~dB}$ in between the antennas printed. So as to improve the isolation, the UWB and NB antennas are to be separated by more than half a wavelength without compromising the compactness. Here the UWB is designed as an electric source, whereas NB antennas as magnetic sources that lead to a fundamentally orthogonal design or an orthogonal characteristic mode [55]. In order to ensure better isolation between antennas, various techniques are suggested by the researchers such as, placement of antennas opposite to each other [56], with defected ground structures [57], by introducing additional decouplers [58]. But these methods have their own limitations in terms of the antenna size. The compactness shall not be guaranteed. The comparison of the referred antennas such as the antenna dimension, UWB coverage by the antenna in $\mathrm{GHz}$, Different NBs the antenna covers by frequency reconfiguration are listed in Table 4. It is observed that all the reported antennas cover the entire UWB, and the antennas in [11], [54] fully cover the UWB as NBs, through excitation switching reconfiguration, in both simulations and measurements maintaining compactness in size.

Table 4 The comparison of Excitation switching reconfigurable antennas.

\begin{tabular}{clll}
\hline Reference & Antenna dimension & $\begin{array}{c}\text { UWB coverage } \\
\text { (GHz) }\end{array}$ & \multicolumn{1}{c}{ NB coverage (GHz) } \\
\hline$[11]$ & $40 \times 36 \times 1.6 \times 10^{3}$ & 3.1 to 10.6 & $\begin{array}{l}3.06 \text { to } 4.23,4 \text { to } 6.37,6.33 \text { to } 8.83,8.7 \text { to } 9.92, \\
\end{array}$ \\
& & 3.82 to 10.74 \\
$453]$ & $30 \times 30 \times 1.6 \times 10^{3}$ & 3.1 to 10.6 & $\begin{array}{l}4 \text { bands in } 6 \text { to } 10 \text { spectra } \\
2.96 \text { to } 5.38,5.31 \text { to } 8.62,8.48 \text { to } 11.02\end{array}$ \\
\hline 54$]$ & $42 \times 50 \times 0.8 \times 10^{3}$ & 3.1 to 10.6 &
\end{tabular}

\section{Comparison of Reconfiguration Techniques}

The reconfiguration techniques discussed so far through various reported works can be compared in terms of speed of switching, requirement of power, isolation, associated losses, reliability, complexity, etc. Frequency reconfiguration using electronic switching components especially PIN diodes has been the most popular one among the works in this area. Faster switching of order nanoseconds can be contributed by PIN diodes and varactors. They are nonlinear in nature where MEMS switches exhibit linearity as well as better isolation. The lower insertion loss and higher activation voltage are the other characteristics of the electronic switches. On the whole, the electrical switches are easy to implement and are of low cost. But this technique is limited due to the presence of biasing lines or circuitry associated with the switching which may adversely affect the radiations from the antenna. Along with this, the switches increase the heaviness and thus the complexity of the antenna [12-38]. However, with proper switching configuration, low VSWR $(<2)$ can be maintained in a wider range of frequencies. The failures or the location of the switches does not affect the VSWR values [39].

The optical switches are found to have faster-switching nature, good isolation, and hence fewer losses. Also, these switches consume low current and voltage for activation. No bias lines are needed and the antennas are reported with reduced complexity as laser diodes are integrated into the antenna itself, in some designs. Otherwise, the activation mechanism of switches is reportedly complicated [40-45].

Physically reconfigurable structures do not need bias lines, optical fibers or laser diodes for the working, but the cost, size, power requirement, increased complexity of the design due to additional circuitry like stepper motor and slower switching limits the performance of these antennas [46-50]. 
http://wjst.wu.ac.th

Reconfiguration using smart materials are advantageous with respect to their small sizes and lighter weights but they are found to have less efficiency specifically at microwave frequencies [51].

The antenna designs as a whole for CR applications discussed with the above 4 techniques have a common characteristic. All those systems allow only a single communication at a time in between a UWB and an NB antenna. In such a scenario, the spectrum utilization efficiency cannot be enhanced. Whereas, in excitation switching reconfiguration, the combination of $1 \mathrm{UWB}$ and more than $1 \mathrm{NB}$ antennas allows simultaneous communication in between the antennas at a time which eventually increases the spectrum utilization. The increase in the number of NB antennas may adversely affect the system size, but this is found to be far better than the disadvantages of the other techniques. The other advantages in addition to the efficient spectrum usage can be counted as RF energy harvesting can be done with the NB antennas when the corresponding frequency spectrum is in usage by the primary user. The NB antennas can be utilized for CR MIMO applications, subjected to modifications. The other reconfigurable techniques also can be added to this architecture. Comparing to other reconfiguration techniques, these antennas found to cover the entire UWB as NBs, more prominently. The challenges in such designs are reported to be good isolation between UWB and NB antennas, proper switching of the antenna, and reduced size. Isolation between antennas is found to improve when the antenna is placed in opposite directions, defected ground planes, and by use of decouplers [52-58].

Practical aspects of the implementation of reconfiguration such as automation and control are dealt in [59]. The reduction of switches, minimization of power losses, optimization, reliability increase, etc. are discussed with mathematical programming. As mathematical programming is time-consuming, for larger networks, meta-heuristics provide a faster way of operation at the cost of accuracy.

\section{Conclusion}

This paper has gone through all the reported reconfiguration techniques for CR. Some antennas are acting as Frequency reconfigurable antennas to be used in the communicating part of CR. Whereas, a few consist of both sensing and communicating parts on the same substrate, but as separate antennas. The $3^{\text {rd }}$ category of antennas is found to have a single port design i.e., both sensing and communication are done by a single antenna. For all of these techniques, any of the antenna require reconfigurable methods, Electrically, Optically, Physically, by the usage of Smart materials and with Excitation Switching reconfiguration, the most recent one. The electrical reconfiguration is achieved with any of the electronic switches such as MEMS, PIN diodes, Varactors, FET switches, etc. and the optical reconfiguration is achieved by photoconductive switches. Physical reconfiguration is attained by a physical variation to the structure and some smart materials are also contributing to the reconfiguration. Finally, the most recent technique, excitation switching reconfiguration is presented where switching in excitation decides which one of the antennas can communicate with the sensing antenna. A number of antennas are surveyed based on their size, UWB and NB coverages, complexity, associated losses, switching speed, isolation, power requirements, efficiency, etc. Analyzing the pros and cons of each technique, this paper provides a solid platform for the researchers to continue their work according to their application constraints.

The reconfigurable antennas are expected to adapt to the surroundings on their own and to establish an energy-efficient link of communication between the devices. The future of the reconfiguration technique lies in the software-defined control and machine learning capability of the antenna system. Reconfiguration techniques may further be extended to wearable antennas that need multi-band operation.

\section{References}

[1] Federal Common. Comm. Spectrum Policy Task Force Report. (Report No. 02-135). Washington DC, ET Docket, 2002.

[2] Y Liang, K Chen, GY Li and P Mahonen. Cognitive radio networking and communications: An overview. IEEE Trans. Veh. Technol. 2011; 60, 3386-407.

[3] J Mitola and GQ Maguire. Cognitive radio: Making software radios more personal. IEEE Pers. Commun. 1999; 6, 13-8. 
http://wjst.wu.ac.th

[4] W Beibei and KJR Liu. Advances in cognitive radio networks: A survey. IEEE J. Sel. Topics Signal Process. 2011; 5, 5-23.

[5] CG Christodoulou. Cognitive radio: The new frontier for antenna design. IEEE AP-S Feature Artic. 2009.

[6] Federal Communication Commission. (2002). $1^{\text {st }}$ Report and Order on Ultra-Wideband Technology. (Report No. 98-153) Washington DC, ET Docket.

[7] HN Awl, YI Abdulkarim, L Deng, M Bakır, FF Muhammadsharif, M Karaaslan, E Unal and H Luo. Bandwidth improvement in Bow-tie microstrip antennas: The effect of substrate type and design dimensions. Appl. Sci. 2020; 10, 504.

[8] Y Tawk, M Bkassiny, G El-Howayek, SK Jayaweera, K Avery and CG Christodoulou. Reconfigurable front-end antennas for cognitive radio applications. IET Microw. Antennas Propag. $2011 ; \mathbf{5}, 985-92$.

[9] W Lee, H Kim and YJ Yoon. Reconfigurable slot antenna with wide bandwidth. In: Proceedings of the IEEE APS International Symposium, Albuquerque, 2006, p. 3063-6.

[10] CG Christodoulou, Y Tawk, SA Lane and SR Erwin. Reconfigurable antennas for wireless and space applications. Proc. IEEE 2012; 100, 2250-61.

[11] N Anvesh Kumar and AS Gandhi. A 5 Port Integrated UWB and narrow band antennas system design for CR applications. IEEE Trans. Antennas Propag. 2018; 66, 1669-76.

[12] AA Ibrahim, A Batmanov and EP Burte. Design of Reconfigurable Antenna using RF MEMS Switch for Cognitive Radio Applications. In: Proceedings of the Progress in Electromagnetics Research Symposium. Spring, St. Petersburg, 2017, p. 369-76.

[13] R George, CRS Kumar and SA Gangal. Design of a frequency reconfigurable pixel patch antenna for cognitive radio applications. In: Proceedings of the International Conference on Communication and Signal Processing. Melmaruvathur, 2016, p. 1684-8.

[14] H Rajagopalan, JM Kovitz and Y Rahmat-Samii. MEMS reconfigurable optimized E-shaped patch antenna design for cognitive radio. IEEE Trans. Antennas Propag. 2014; 62, 1056-64.

[15] S Nikolaou, N Kingsley, G Ponchak, J Papapolymerou and M Tentzeris. UWB elliptical monopoles with a reconfigurable band notch using MEMS switches actuated without bias lines. IEEE Trans. Antennas Propag. 2009; 57, 2242-51.

[16] G Srivastava, A Mohan and A Chakrabarty. Compact reconfigurable UWB slot antenna for cognitive radio applications. IEEE Antennas Wireless Propag. Lett. 2017; 16, 1139-42.

[17] GA Devi, J Aarthi, P Bhargav, R Pandeeswari, MA Reddy and RS Daniel. UWB frequency reconfigurable patch antenna for cognitive radio applications. In: Proceedings of the IEEE International Conference on Antenna Innovations and Modern Technologies for Ground, Aircraft and Satellite Applications. 2017, p. 1-4.

[18] C Gupta, D Maheshwari, RK Saraswat and M Kumar. A UWB frequency-band reconfigurable antenna using switchable slotted ground structure. In: Proceedings of the $4^{\text {th }}$ International Conference on Communication Systems and Network Technologies. Bhopal, India, 2014, p. $20-4$.

[19] S Pahadsingh, S Sahu and S Das. Compact ultrawideband-reconfigurable antenna for cognitive radio platforms. In: Proceedings of the International Conference on Wireless Communications, Signal Processing and Networking. 2017, p. 2735-8.

[20] G Augustin, BP Chacko and TA Denidni. Electronically reconfigurable uni-planar antenna for cognitive radio applications. IET Microw. Antennas Propag. 2014; 8, 367-76.

[21] L Ge and KM Luk. Band-reconfigurable unidirectional antenna: A simple, efficient magnetoelectric antenna for cognitive radio applications. IEEE Antennas Propag. Mag. 2016; 58, 18-27.

[22] NV Soumya and PR Anurenjan. Switched-band Vivaldi antenna with hexagonal slots for cognitive radio applications. In: Proceedings of the IEEE Annual India Conference. 2016, p. 1-4.

[23] N Kumar, P Ananda Raju and SK Behera. Frequency reconfigurable microstrip antenna for cognitive radio applications. In: Proceedings of the International Conference on Communications and Signal Processing. Melmaruvathur, India. 2015, p. 370-3.

[24] L Pazin and Y Leviatan. Reconfigurable slot antenna for switchable multiband operation in a wide frequency range. IEEE Antennas Wireless Propag. Lett. 2013; 12, 329-32. 
http://wjst.wu.ac.th

[25] MG Aly and Y Wang. An integrated narrow band wide band antenna. In: Proceedings of the IEEE Loughborough Antennas and Propagation Conference, UK, 2013, p. 433-5.

[26] FD Dahalan, SKA Rahim, MR Hamid, MA Rahman, MZM Nor, MSA Rani and PS Hall. Frequency reconfigurable archimedean spiral antenna. IEEE Antennas Wireless Propag. Lett. 2013; 12, 1504-7.

[27] A Kalteh, G DadashZadeh, M Naser-Moghadasi and B Virdee. Ultra-wideband circular slot antenna with reconfigurable notch band function. IET Microw. Antennas Propag. 2012; 6, 108-12.

[28] H Boudaghi, M Azarmanesh and M Mehranpour. A frequency reconfigurable monopole antenna using switchable slotted ground structure. IEEE Antennas Wireless Propag. Lett. 2012; 11, 655-8.

[29] HF Abutarboush, S Khan, R Nilavalan, HS Al-Raweshidy and D Budimir. Reconfigurable wideband patch antenna for cognitive radio. In: Proceedings of the IEEE Loughborough Antennas and Propagation Conference. UK, 2009, p. 141-4.

[30] MC Tang, Z Wen, H Wang, M Li and RW Ziolkowski. Compact, frequency reconfigurable filtenna with sharply defined wideband and continuously tunable narrowband states. IEEE Trans. Antennas Propag. 2017; 65, 5026-34.

[31] R Hussain, MS Sharawi and A Shamim. An integrated 4-element slot-based MIMO and a UWB sensing antenna system for CR platforms. IEEE Trans. Antennas Propag. 2018; 66, 978-83.

[32] PY Qin, F Wei and YJ Guo. A wideband-to narrowband tunable antenna using a reconfigurable filter. IEEE Trans. Antennas Propag. 2015; 63, 2282-5.

[33] T Aboufoul, A Alomainy and C Parini. Reconfiguring UWB monopole antenna for cognitive radio applications using GaAs FET switches. IEEE Antennas Wireless Propag. Lett. 2012; 11, 392-4.

[34] EJB Rodrigues, HWC Lins and AGD Assuncao. Recongurable circular ring patch antenna for UWB and cognitive radio applications. In: Proceedings of the $8^{\text {th }}$ European Conference on Antennas and Propagation, Hague, Netherlands. 2014, p. 2744-8.

[36] AV Golliwar and MS Narlawar. Multiple controllable band notch butterfly shaped monopole UWB antenna for cognitive radio. In: Proceedings of the World Conference on Futuristic Trends in Research and Innovation for Social Welfare. 2016, p. 1-4.

[37] M Al-Husseini, A El-Hajj, Y Tawk, KY Kabalan and CG Christodoulou. A simple dual-port antenna system for cognitive radio applications. In: Proceedings of the International Conference on High Performance Computing and Simulation. 2010, p. 549-52.

[38] NO Parchin, HJ Basherlou, YIA Al-Yasir, AM Abdulkhaleq and RA. Abd-Alhameed. Reconfigurable antennas: Switching techniques-A survey. Electronics. 2020; 9, 336, 1-14.

[39] K Jagodzinska. On the self-structuring antenna. Sensors 2020; 20, 759.

[40] GP Jin, DL Zhang and RL Li. Optically controlled reconfigurable antenna for cognitive radio applications. Electron. Lett. 2011; 47, 948-50.

[41] A Andy, P Alizadeh, KZ Rajab, T Kreouzis and R Donnan. An optically-switched frequency reconfigurable antenna for cognitive radio applications. In: Proceedings of the $10^{\text {th }}$ European Conference on Antennas and Propagation. 2016, p. 1-4.

[42] SH Zheng, XY Liu and MM Tentzeris. A novel optically controlled reconfigurable antenna for cognitive radio systems. In: Proceedings of the IEEE AP-S International Symposium. 2014, p. 1246-7.

[43] SH Zheng, XY Liu and MM Tentzeris. Optically controlled reconfigurable band-notched UWB antenna for cognitive radio systems. Electron. Lett. 2014; 50, 1502-4.

[44] D Zhao, L Lan, Y Han, F Liang, Q Zhang and BZ Wang. Optically controlled reconfigurable bandnotched UWB antenna for cognitive radio applications. IEEE Photon. Technol. Lett. 2014; 26, 2173-6.

[45] Y Tawk, J Costantine, S Hemmady, G Balakrishnan, K Avery and CG Christodoulou. Demonstration of a cognitive radio front end using an optically pumped reconfigurable antenna system (OPRAS). IEEE Trans. Antennas Propag. 2012; 60, 1075-83.

[46] P Tummas, P Krachodnok and R Wongsan. A frequency recongurable antenna design for UWB applications. In: Proceedings of the $11^{\text {th }}$ International Conference on Electrical engineering Electronics, Computer, Telecommunications and Information Technology, Nakhon Ratchasima, Thailand, 2014, p. 1-4. 
http://wjst.wu.ac.th

[47] Y Tawk, J Costantine and CG Christodoulou. A rotatable reconfigurable antenna for cognitive radio applications. In: Proceedings of the IEEE Radio and Wireless Symposium. Phoenix, Arizona, USA, 2011, p. 158-61.

[48] Y Tawk, J Costantine, K Avery and CG Christodoulou. Implementation of a cognitive radio frontend using rotatable controlled reconfigurable antennas. IEEE Trans. Antennas Propag. 2011; 59, 1773-8.

[49] Y Tawk and CG Christodoulou. A new reconfigurable antenna design for cognitive radio. IEEE Antennas Wireless Propag. Lett. 2009; 8, 1378-81.

[50] Y Tawk, J Costantine and CG Christodoulou. A frequency reconfigurable rotatable microstrip antenna design. In: Proceedings of the IEEE AP-S International Symposium. Toronto, 2010, p. 1-4.

[51] AD Conceifo Andrade, IP Fonseca, SF Jilani and A Alomainy. Reconfigurable textile-based ultrawideband antenna for wearable applications. In: Proceedings of the $10^{\text {th }}$ European Conference on Antennas and Propagation. Davos, 2016, p. 1-4.

[52] N Anvesh Kumar and AS Gandhi. A survey on planar antenna designs for cognitive radio applications. Wirel. Pers. Commun. 2018; 98, 541-69.

[53] N Anvesh Kumar and AS Gandhi. A compact novel 3-port integrated wide and narrow band antennas system for cognitive radio applications. Int. J. Antenn. Propag. 2016; 2016, 1-14.

[54] O Yeonjeong, Y Jin and J Choi. A compact 4-port coplanar antenna based on an excitation switching reconfigurable mechanism for cognitive radio applications. Appl. Sci. 2019; 9, 16.

[55] J Chen, M Berg, V Somero and A Prssinen. A multiple antenna system design for wearable device using theory of characteristic mode. In: Proceedings of the $12^{\text {th }}$ European Conference on Antennas and Propagation. London, UK, 2018, p. 9-13.

[56] MGN Alsath and M Kanagasabai. Compact UWB monopole antenna for automotive communications. IEEE Trans. Antennas Propag. 2015; 63, 4204-8.

[57] S Shoaib, I Shoaib, N Shoaib, X Chen and CG Parini. Design and performance study of a dualelement multiband printed monopole antenna array for MIMO terminals. IEEE Antennas Wirel. Propag. 2014; 13, 329-32.

[58] $\mathrm{C} \mathrm{Wu}, \mathrm{C}$ Chiu and $\mathrm{T} \mathrm{Ma}$. Very compact fully lumped decoupling network for a coupled 2-element array. IEEE Antennas Wirel. Propag. 2016; 15, 158-61.

[59] AEB Abu-Elanien, MMA Salama and KB Shaban. Modern network reconfiguration techniques for service restoration in distribution systems: A step to a smarter grid. Alex. Eng. J. 2018; 57, 3959-67. 